\title{
Volcanic effects on climate: revisiting the mechanisms
}

\author{
H.-F. Graf ${ }^{1}$, Q. Li ${ }^{2}$, and M. A. Giorgetta ${ }^{2}$ \\ ${ }^{1}$ Centre for Atmospheric Science, University of Cambridge, UK \\ ${ }^{2}$ Max-Planck-Institute for Meteorology, Hamburg, Germany
}

Received: 24 January 2007 - Published in Atmos. Chem. Phys. Discuss.: 22 March 2007

Revised: 1 August 2007 - Accepted: 27 August 2007 - Published: 30 August 2007

\begin{abstract}
The characteristics of planetary wave energy propagation are being compared based on NCEP reanalysis data from 1958 to 2002 between boreal winters after strong volcanic eruptions, non-volcanic winters and episodes of strong polar vortex lasting at least 30 days. It shows that in the volcanically disturbed winters much more planetary wave energy is produced in the troposphere, passes through the lowermost stratosphere and enters the upper stratosphere than in any other times. This is contradicting earlier interpretations and model simulations. Possibly the observed El Ninos coinciding with the three significant eruptions in the second half of the 20th century contributed to the planetary wave energy. In order to produce the observed robust climate anomaly patterns in the lower troposphere, these planetary waves are suggested to be reflected near the stratopause instead of breaking. While a strong polar vortex is observed after volcanic eruptions in the stratosphere and in the troposphere, specific episodes of strong polar vortex regime exhibit much stronger anomalies and different dynamics. Hence it is suggested that the climate effects of volcanic eruptions are not being explained by the excitation of inherent zonal mean variability modes such as Strong Polar Vortex or Northern Annular Mode, but rather is another mode that possibly reflects upon the North Atlantic Oscillation.
\end{abstract}

\section{Introduction}

Large volcanic eruptions can produce climatic anomalies over several years. While earlier studies concentrated on global or zonal mean anomalies resulting in relatively small signals (Angell and Korshover, 1985, Bradley, 1988, Mass and Portmann, 1990), after the eruption of Mt. Pinatubo also the patterns of climate anomalies following volcanic erup-

Correspondence to: $\mathrm{H} .-\mathrm{F}$. Graf

(hfg21@cam.ac.uk) tions were considered leading to the detection of the so called "continental winter warming" in observations of surface temperature anomalies (a.o. Groisman, 1992; Robock and Mao, 1992; Kelly et al., 1996) and also in global circulation models (a.o. Graf et al., 1993; Kirchner et al., 1999; Mao and Robock, 1998; Schindell et al., 2001), which is very similar to climate anomalies during winters with a positive anomaly of the North Atlantic Oscillation index. The early model simulations led to a dynamic interpretation of the zonally inhomogeneous tropospheric climate anomalies (Graf, 1992; Graf et al., 1993; Kodera, 1994) that was adopted and further developed (e.g. Stenchikov et al., 2002) in most of the subsequent investigations until today. Basically the interpretation was such that differential heating between low and high latitudes in the sulphate aerosol laden stratospheric layer would lead to strengthened westerlies in subpolar and midlatitudes in winter, i.e. a strengthened polar vortex. These strong westerlies prevent planetary waves from penetrating into the higher stratosphere and their reflection back to the troposphere creates a circulation pattern responsible for warm air advection over the continents of the Northern Hemisphere. Since the anomaly patterns are very similar to those that are observed in winters with strong positive anomalies of the leading atmospheric variability modes (Arctic Oscillation or Northern Annular Mode index) which happen to be very similar with the anomaly patterns of winters with strong positive North Atlantic Oscillation index, the ready interpretation was that volcanic aerosol in the stratosphere excites a specific phase of these variability modes. More recently, Stenchikov et al. 2002 extended this interpretation and introduced two different mechanisms, one originating in the stratosphere (combining the effects of sulphate aerosol and reduced ozone to force the polar vortex), one in the troposphere, where reduced meridional differential heating would lead to less vertical planetary wave energy flux. Both mechanisms reinforce each other leading to a stable and strong climate signal. 
Table 1. Periods of polar vortex regimes: (a) strong polar vortex regime (SVR) and (b) weak polar vortex regime (WVR) (NCEP/NCAR RA 1958 to 2002).

\begin{tabular}{ll}
\hline Starting dates & Ending dates \\
\hline $1959 / 01 / 22$ & $1959 / 03 / 07$ \\
$\mathbf{1 9 6 3 / 1 2 / 2 4}$ & $\mathbf{1 9 6 4 / 0 2 / 2 8}$ \\
$1967 / 01 / 03$ & $1967 / 03 / 31$ \\
$1975 / 12 / 01$ & $1976 / 03 / 24$ \\
$1987 / 11 / 20$ & $1987 / 01 / 14$ \\
$1988 / 12 / 16$ & $1989 / 02 / 17$ \\
$1989 / 12 / 17$ & $1990 / 03 / 31$ \\
$1990 / 11 / 02$ & $1990 / 12 / 29$ \\
$\mathbf{1 9 9 1 / 1 1 / 2 4}$ & $\mathbf{1 9 9 2 / 0 1 / 1 8}$ \\
$\mathbf{1 9 9 2 / 1 2 / 0 5}$ & $\mathbf{1 9 9 3 / 0 2 / 1 1}$ \\
$1994 / 11 / 26$ & $1995 / 01 / 18$ \\
\hline
\end{tabular}

Very recently, two papers were published (Stenchikov et al., 2006 and Miller et al., 2006) that investigate the performance of state of the art climate models in reproducing observed climate anomalies after volcanic eruptions. The model data for both studies were taken from the IPCC AR4 archive of historic simulations including some of the strongest volcanic eruptions of the late 19th and 20th centuries. Both studies find that while the models basically react with the right sign of annular (Miller et al., 2006) and NAO pattern (Stenchikov et al., 2006) they severely underestimate the amplitude of the response. This leads to much smaller areas of statistical significance of the anomalies than in the real world. Reasons for this behaviour remain speculative and include missing tropospheric and stratospheric processes. At the centre of interest are planetary waves and their interaction with the background flow. Therefore, here we will add to the discussion by looking at the conditions of vertical planetary wave propagation in winters with and without volcanic forcing.

We distinguish between breaking of planetary waves and their reflection. Wave breaking can occur when a wave packet is propagating into the high stratosphere, where its amplitude increases and it finally breaks. This process obviously is eased and the chances of wave packets reaching the breaking region are higher when the polar vortex is relatively weak. Wave breaking will produce a zonal symmetric anomaly as it affects the mean atmospheric circulation. A typical example is (major) stratospheric warming. Wave reflection can occur at very high wind speeds in the lower stratosphere or upper troposphere and will depend on zonal wave number (ZWN) and the state of the atmosphere (Charney and Drazin, 1961) or at layers with strong negative wind shear, mostly in the upper stratosphere (Perlwitz and Harnik, 2003). The refractive index developed by Matsuno (1970) is an effective means to describe the conditions for planetary wave propagation. Wave reflection will affect the phase

\begin{tabular}{ll}
\hline Starting dates & Ending dates \\
\hline $1958 / 01 / 26$ & $1958 / 03 / 31$ \\
$1960 / 11 / 01$ & $1960 / 12 / 27$ \\
$1963 / 02 / 08$ & $1963 / 03 / 13$ \\
$1965 / 11 / 12$ & $1965 / 12 / 25$ \\
$1968 / 12 / 20$ & $1969 / 01 / 27$ \\
$1981 / 02 / 26$ & $1981 / 03 / 30$ \\
$1984 / 12 / 28$ & $1985 / 02 / 13$ \\
$1987 / 11 / 24$ & $1987 / 12 / 28$ \\
$1996 / 11 / 14$ & $1996 / 12 / 22$ \\
$1998 / 12 / 09$ & $1999 / 01 / 11$ \\
$2000 / 11 / 08$ & $2000 / 12 / 22$ \\
$2001 / 02 / 04$ & $2001 / 03 / 31$ \\
\hline
\end{tabular}

and amplitude of planetary waves in the troposphere, hence is connected with a zonally non-symmetric anomaly pattern like the North Atlantic Oscillation (NAO).

\section{Data and analysis method}

In order to study planetary waves and their propagation characteristics three-dimensional atmospheric data are necessary. We use the NCEP/NCAR reanalysis data for the 45 years 1958-2002 (Kalnay et al., 1996; Kistler et al. 2001) at daily resolution for geopotential height, wind and temperature on a 2.5-degree grid at the 17 vertical levels between $1000 \mathrm{hPa}$ and $10 \mathrm{hPa}$. During this time only three climatically relevant tropical volcanic eruptions occurred: Gunung Agung in March 1963, El Chichon in May 1982 and Mt. Pinatubo in June 1991. Due to the lifetime of the volcanic aerosol in the stratosphere we consider the two winters (December, January and February) after the eruptions as volcanically disturbed (i.e. DJF 1963/64, 1964/65, 1982/83, 1983/84, 1991/92, 1992/93). All other winters are taken as the volcanically undisturbed cases. Since winters after volcanic eruptions are said to be characterized by strong polar vortices, we also consider those periods when the polar vortex is strong. We define these periods as the strong polar vortex regime (SVR) when winds at $65^{\circ} \mathrm{N}$ and $50 \mathrm{hPa}$ exceed $20 \mathrm{~m} / \mathrm{s}$ for at least 30 days (Castanheira and Graf, 2003) and give their start and end date in Table 1. In addition we define the weak polar vortex regimes (WVR) when the winds are weaker than $10 \mathrm{~m} / \mathrm{s}$, but still westerly, hence excluding major stratospheric warmings. As one can see from Table 1, there were $11 \mathrm{SVR}$ and 12 WVR periods. Three of the $11 \mathrm{SVRs}$ are in winters with volcanic disturbance (marked bold in Table 1), after El Chichon there was no SVR observed, but both post-Pinatubo winters had extended SVRs and so had the first winter after the Gunung Agung eruption. None of the WVRs occurred in 

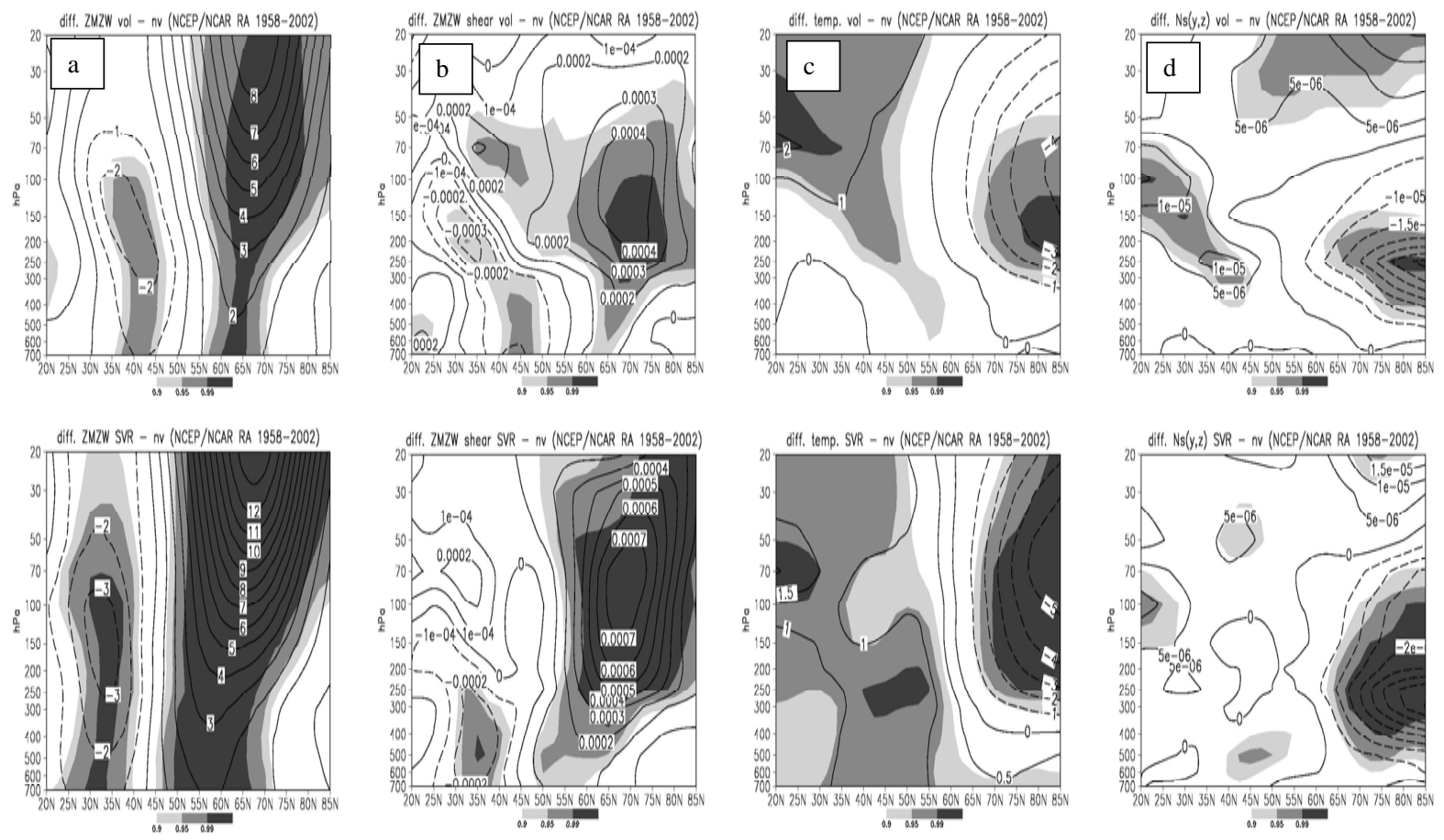

Fig. 1. Zonal mean anomalies of (a) zonal wind, (b) vertical wind shear, (c) zonal mean temperature, (d) stability for volcanic winters (top row) and SVR episodes (excluding volcanic winters, bottom row) minus non-volcanic winters. Light, medium and dark shading indicate statistical significance (t-test) at $90 \%, 95 \%$ and above $99 \%$.

winters after any of the eruptions and in no one winter both regimes are observed.

For volcanic winters, non-volcanic winters and nonvolcanic SVRs north of $20^{\circ} \mathrm{N}$ we calculated the stationary wave related transport of energy, the Eliassen-Palm (EP) flux, in its quasi-geostrophic version (Andrews et al., 1987) and the divergence of EP flux. Negative divergence (or convergence) of EP flux leads to deceleration of the westerly winds. Since planetary waves tend to be refracted from areas with a negative refractive index squared (Matsuno, 1970) we also show the frequency of negative squared refractive indices on the meridional plane (Li et al., 2006) describing the potential probability for planetary waves propagating in the meridional plane for zonal wave numbers 1-3. This probability depends not only on the zonal mean zonal wind, but also on vertical stability and vertical wind shear. Whenever we talk about planetary waves in this study, we mean stationary planetary waves. We used t-test throughout where appropriate but the small number of cases clearly reduces the applicability of statistical analysis.

\section{Results}

Planetary wave propagation depends on the vertical profiles of wind, wind shear and static stability. In Fig. 1, top row, are shown the differences between volcanic winters and all non-volcanic winters for a) zonal mean zonal wind, b) vertical wind shear, c) zonal mean temperature and d) vertical stability parameter (Nyquist frequency). Clearly a statistically significantly (t-test, $>99 \%$ ) stronger polar vortex is seen penetrating from the stratosphere down to the troposphere. A weaker subtropical jet accompanies this strong polar vortex as is known from former studies (Feser et al., 2000, Kodera et al., 1991). Vertical wind shear is enhanced in the lower stratosphere, mainly north of $60^{\circ} \mathrm{N}$ but extending to the subtropics. Significantly higher temperatures are found in the stratosphere in low and midlatitudes and cooling concentrates at the tropopause and lower stratosphere inside the polar circle, which may be an indication of reduced strength of the Brewer-Dobson circulation due to less planetary wave breaking in the stratosphere. The vertical stability is reduced below the polar center of cooling and enhanced above, as well as below the low latitude stratospheric warm anomaly. Similar patterns, although overlaid by some variability, are found in all individual winters after the eruptions (not shown here). The winter 1992/93 has the least enhanced polar vortex due to a mid-January near major stratospheric warming. For the periods of SVR (Fig. 1, bottom row) the patterns are similar, but the amplitudes are much greater, except for the stability parameter, which is more enhanced in the volcanic case in the midlatitudes and subtropics in the upper troposphere and lower stratosphere, respectively. It 

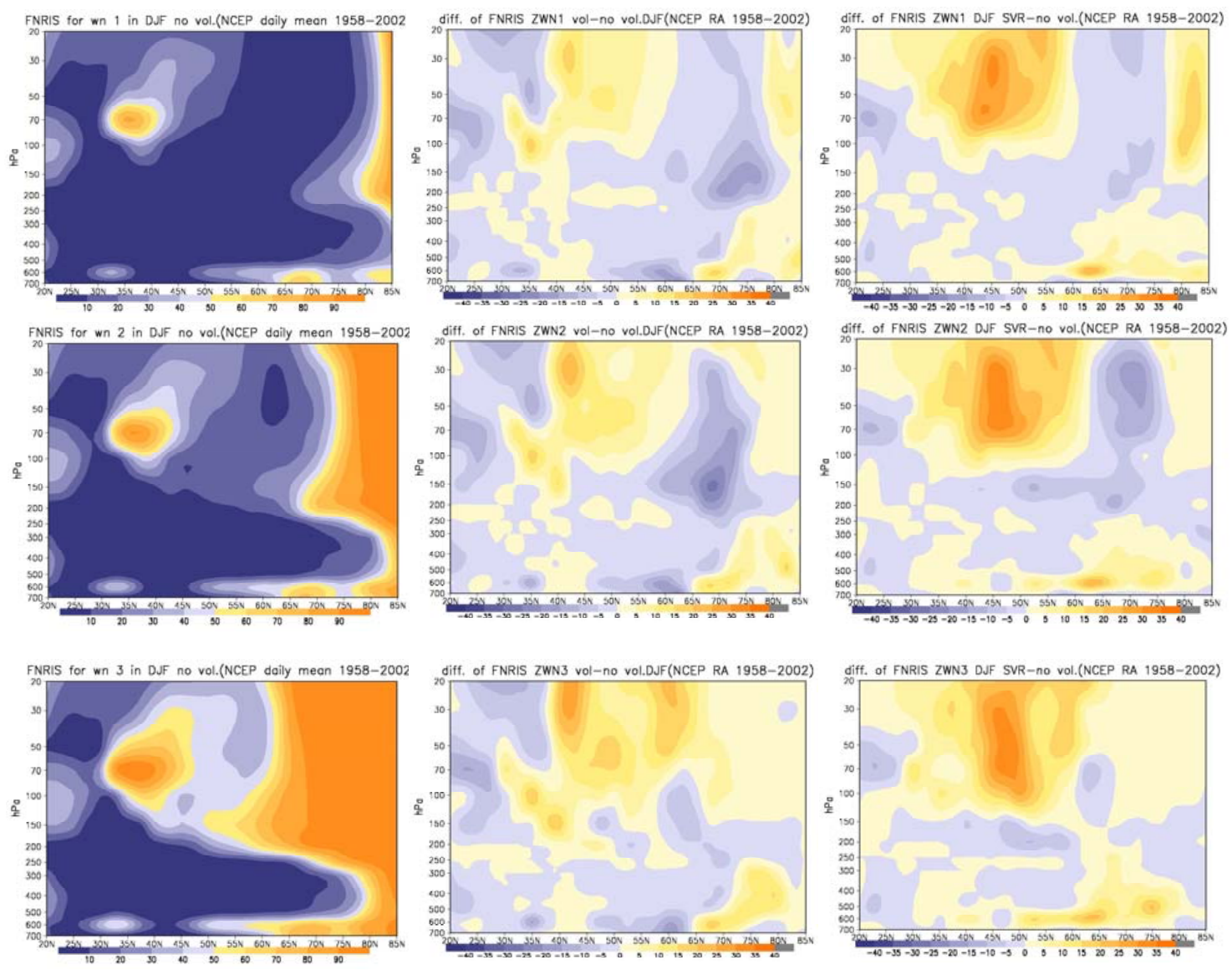

Fig. 2. Frequency of negative squared refractive indices for stationary waves top row: ZWN 1, middle row ZWN 2, bottom row: ZWN 3 for non-volcanic winters (left column). Middle and right column are frequency differences between non-volcanic winters and volcanic winters and SVR episodes, respectively. Unit is \%.

is interesting that the stratospheric meridional temperature gradient is enhanced both in volcanic winters and in SVR episodes, but major differences are observed in the troposphere. The troposphere is significantly warmer also in mid and low latitudes during SVR, but very little anomalies are found in volcanic winters. Thus the meridional temperature gradient is enhanced in troposphere and stratosphere in SVR, but only in the stratosphere in volcanic winters. This is due to the stronger reduction of shortwave radiation reaching the ground in lower latitudes (see also Stenchikov et al. 2002). In general, except for the vertical stability parameter, anomalies are much stronger in SVR episodes than for volcanic winters. This indicates that the idea that volcanic eruptions would excite especially sustained positive anomalies of Northern Annular Mode or North Atlantic Oscillation may not be supported.

In Fig. 2 the frequency of negative squared refractive indices is shown for the meridional plane from $20^{\circ} \mathrm{N}$ to $85^{\circ} \mathrm{N}$ and from the lower troposphere to $20 \mathrm{hPa}$. Frequencies below $50 \%$ are blue coloured. The lower this frequency is the higher is the possibility for a planetary wave to propagate through the respective area. In the dark orange areas practically all planetary waves are blocked. As one can see, the best possibilities are given for ZWN1 waves to propagate from the troposphere to the stratosphere. The higher the wave numbers are the lower are the chances of a wave to enter higher altitudes. This result is in full agreement with standard conceptual ideas. Using the frequency instead of the mean refractive index provides a much smoother and easier to interpret pattern ( $\mathrm{Li}$ et al., 2006). The second (third) column of Fig. 2 represents the frequency differences of negative squared refractive indices between volcanic winters (SVR episodes) and non-volcanic winters. These results are somewhat unexpected, at least for ZWN1 and 2. While during volcanic winters and SVR episodes the zonal mean zonal wind is much enhanced around the polar circle, which would, according to the Charney-Drazin Theorem (Charney and Drazin, 1961), lead to a reduction of planetary wave propagation, we find reduced frequency of the negative squared refractive index, i.e. a greater chance for planetary 


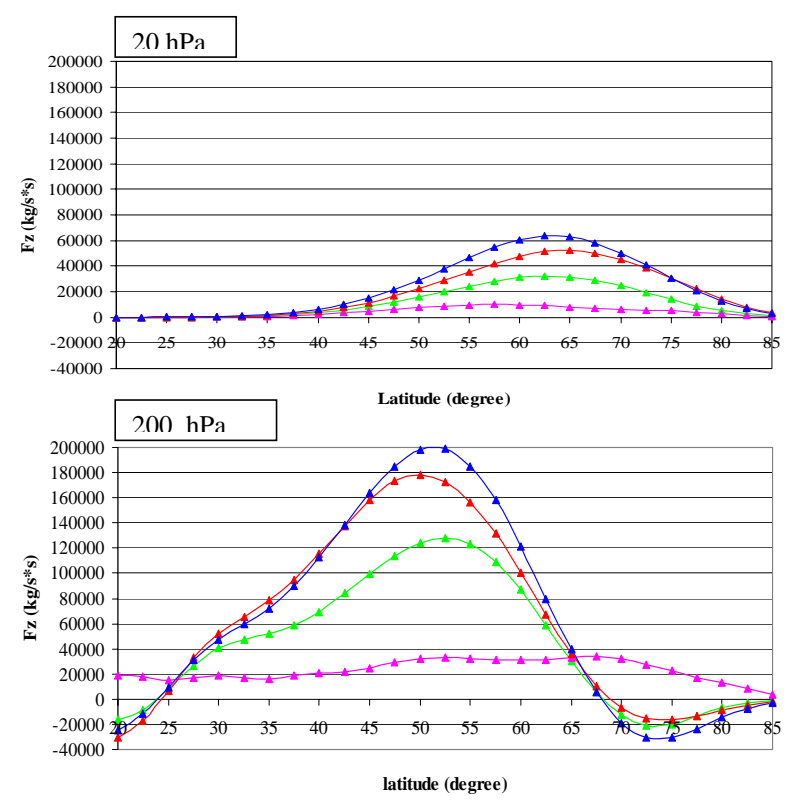

- SVR $₫$ SVR standard deviation $₫$ general winter (no vol.) $₫$ volcanic winter

Fig. 3. Meridional profiles of the vertical component of $\mathrm{ZWN} 1+2+3$ related EP flux (kg/s ${ }^{2}$ ) across the $20 \mathrm{hPa}$ (top) and $200 \mathrm{hPa}$ (bottom) layers in SVR episodes, non-volcanic winters and volcanic winters and standard deviation of SVR EP flux.

waves to travel into the higher stratosphere at high northern latitudes above $60^{\circ} \mathrm{N}$. South of this latitude the chances to propagate up are reduced. From the position of the positive stratospheric zonal wind anomaly in volcanically disturbed winters (Fig. 1a, upper row) one might expect splitting of planetary wave propagation into branches propagating into very high latitudes and into lower latitudes. For ZWN3 the frequency of a refractive index prohibiting propagation is enhanced everywhere in the stratosphere north of $30^{\circ} \mathrm{N}$. However, an analysis of the refractive index alone cannot answer the question if there is more or less wave propagation since it does not contain information on the planetary waves themselves. Therefore we will look at the vertical component of the total EP flux of ZWN1-3 at two different altitudes: 200 and $20 \mathrm{hPa}$ (Fig. 3). In this figure the meridional profiles of planetary stationary wave related energy fluxes are shown for the non-volcanic winters (red), volcanic winters (blue) and non-volcanic SVR episodes (green). Additionally the standard deviation of the SVR flux (magenta) is shown to give an idea about variability. This standard deviation at all latitudes is much smaller than the absolute fluxes are, excepting at polar latitudes near the tropopause and in very low latitudes. The maximum vertical EP flux in $200 \mathrm{hPa}$ we find at $52.5^{\circ} \mathrm{N}$ for volcanic winters with $200.000 \mathrm{~kg} / \mathrm{s}^{2}$. In nonvolcanic winters and in SVR episodes the maximum verti-
Fz for ZWN1 on 20hPa (DJF, 1958-2002)

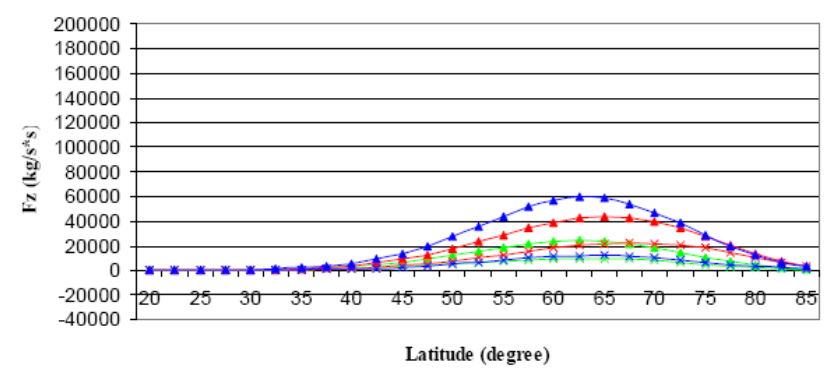

Fz for ZWN2 on 20hPa (DJF, 1958-2002)

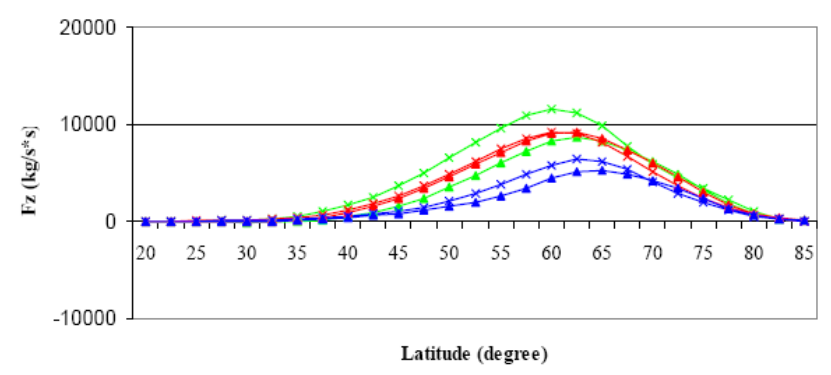

Fig. 4a. Meridional profiles of the vertical component of ZWN1 and ZWN2 related EP flux $\left(\mathrm{kg} / \mathrm{s}^{2}\right)$ and their standard deviations across the $20 \mathrm{hPa}$ (top) and $200 \mathrm{hPa}$ (bottom) layers in SVR episodes, nonvolcanic winters and volcanic winters and standard deviation of SVR EP flux.

cal EP flux is smaller with 179.000 and ca. $128.000 \mathrm{~kg} / \mathrm{s}^{2}$, respectively. This result contradicts earlier suggestions of Stenchikov et al. (2002) who, based on a series of model runs with the SKYHI model, found slightly reduced ( -5 to $-6 \%)$ vertical EP flux at $400 \mathrm{hPa}$ in the latitude band between $30^{\circ} \mathrm{N}$ and $60^{\circ} \mathrm{N}$ when the model was disturbed by volcanic aerosol in the stratosphere. When we look at the vertical EP flux component at $20 \mathrm{hPa}$, the maximum as expected is shifted to higher latitudes in all three cases. The highest vertical EP flux we again find for the volcanic winters. More than $32 \%$ of the energy flux at $200 \mathrm{hPa}$ reaches the upper stratosphere in volcanic winters. In SVR episodes it is only $25 \%$ and in nonvolcanic winters $28 \%$. Obviously the vertical propagation of planetary waves is somewhat eased in volcanic winters compared with all others, corresponding to the reduced frequency of negative squared refractive indices. An explanation of this behaviour cannot be given based on the frequencies of negative refractive indices alone since then one should also expect a higher percentage of planetary wave energy to arrive at the upper stratosphere during the SVR episodes, which is not the case. The distribution of planetary wave energy over different zonal wave numbers (ZWN) may give some explanation for the unexpected results (Fig. 4). In volcanic winters ZWN1 (Fig. 4a) provides the strongest vertical EP-flux at $200 \mathrm{hPa}$ in the midlatitudes. It contributes $55 \%$ to the total 
Fz for ZWN1 on 200hPa (DJF, 1958-2002)

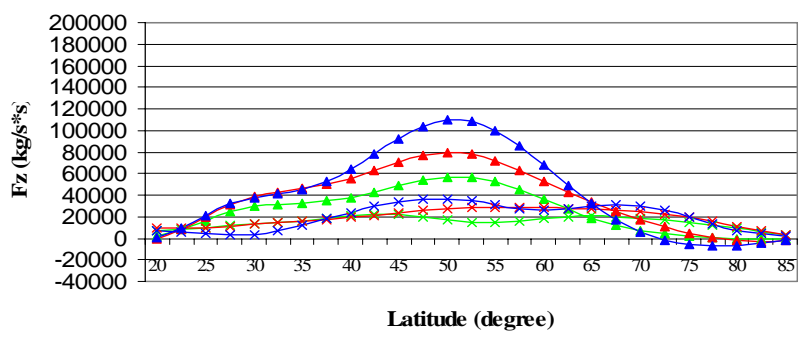

Fz for ZWN2 on 200hPa (DJF, 1958-2002)

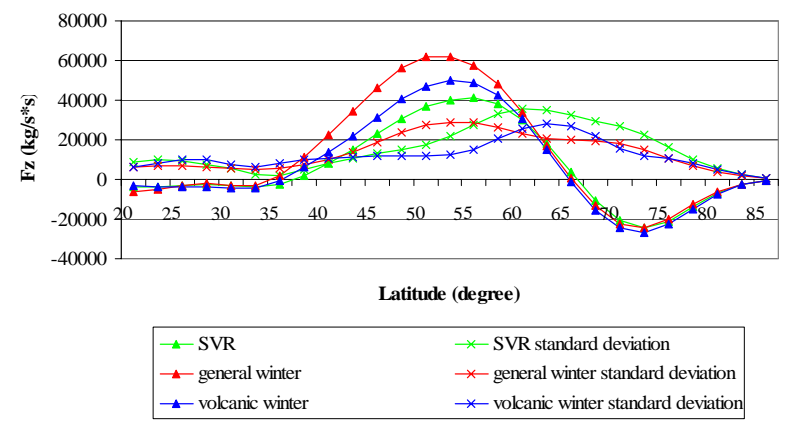

Fig. 4b. EP flux and its divergence $(\mathrm{ZWN} 1+2+3)$ : (a) difference between non-volcanic SVR episodes and non-volcanic winters; (b) difference between volcanic winters and non-volcanic winters. Divergence contour interval is $0.5 \mathrm{~ms}^{-1} \mathrm{day}^{-1}$ the unit of vector is $\mathrm{kg} \mathrm{s}^{-2}$.

ZWN1+2+3 vertical EP-flux between $45^{\circ} \mathrm{N}$ and $60^{\circ} \mathrm{N}$ and $33 \%$ of this flux reach the $20 \mathrm{hPa}$ layer between $55^{\circ} \mathrm{N}$ and $70^{\circ} \mathrm{N}$, where ZWN1 contributes nearly all $(94 \%)$ the vertical EP-flux. Non-volcanic winters have reduced ZWN1 vertical EP-flux at both heights, and non-volcanic SVR episodes have even less. These relationships change significantly for ZWN2 (Fig. 4b). Non-volcanic winters see the maximum of ZWN2 vertical EP-flux crossing the $200 \mathrm{hPa}$ layer, followed by volcanic winters and non-volcanic SVR episodes. However, the smallest rate of ZWN2 vertical EP-flux reaches the upper stratosphere at $20 \mathrm{hPa}$ during volcanic winters $(10 \%)$, followed by non-volcanic winters (15\%) and non-volcanic SVR episodes (22\%), when nearly as much ZWN2 vertical EP-flux reaches the $20 \mathrm{hPa}$ level as in non-volcanic winters. This is not surprising when the reduced frequency of negative squared refraction indices is considered (Fig. 2). Hence, the observed enhanced vertical EP-flux during volcanic winters can be related to enhanced ZWN1 planetary wave activity excited in the troposphere, which is combined with somewhat improved vertical propagation conditions for these ultra long waves. The standard deviations of the vertical EPfluxes are considerable due to high inherent variability and the small number of cases. Thus the statistical significance of these results is limited.
It is obvious from Fig. 2 that planetary waves generated in the midlatitudes in the troposphere have two possibilities to propagate: both upward and slightly poleward into the stratosphere or quasi-horizontally towards the subtropics. Keeping in mind that planetary waves propagate in the direction of the gradient of the refractive index, there are some arguments for planetary waves propagating more towards the subtropics in SVR than in volcanic winters. The zonal winds constituting the polar vortex are much stronger over a wider band of latitudes in SVR episodes than in volcanic winters and they are reaching into lower latitudes. There is a very strong positive vertical wind shear in polar latitudes and the vertical stability parameter is favourable for planetary wave propagation in higher latitudes, but this is not sufficient to overcome the effects of zonal mean wind. Hence, planetary waves will be more attracted by the subtropics in SVR and will penetrate into the upper stratosphere in volcanic winters. EP flux anomaly patterns for SVR episodes and for volcanic winters clearly show this behaviour (Fig. 5). In comparison with non-volcanic winters during non-volcanic SVR episodes we find enhanced upward EP flux only in the lower troposphere and mainly in higher latitudes between $55^{\circ} \mathrm{N}$ and $70^{\circ} \mathrm{N}$ (Fig. 5a). Elsewhere the upward EP flux is greatly decreased, especially in the stratosphere north of $40^{\circ} \mathrm{N}$ and in the troposphere between $35^{\circ} \mathrm{N}$ and $50^{\circ} \mathrm{N}$. In the midlatitudes lower troposphere we find convergence of EP flux and above this very strong divergence in the upper troposphere, increasing the westerlies there. We also find divergence of EP flux near the core of the polar stratospheric vortex with a centre at $70^{\circ} \mathrm{N}$ and $30 \mathrm{hPa}$. Both divergence regions are in agreement with the wide area of enhanced westerlies already reported in Fig. 1a, lower row, for SVR episodes. It is these strong westerlies in the upper troposphere that reduce the EP flux from the troposphere into the stratosphere. In contrast to SVR episodes, during volcanic winters in the troposphere much more stationary planetary wave energy is upwelling mainly in midlatitudes, turning equatorward in the upper troposphere (Fig. 5b). A larger part than in non-volcanic winters and in SVR episodes of this energy is reaching the upper stratosphere. Divergence of EP flux is found in the lower troposphere in midlatitudes that is overlaid in the upper troposphere by convergence of EP flux reaching from the mid to the polar latitudes. Hence, the pattern is opposite to SVR episodes. In the stratosphere divergent EP flux strengthens the polar vortex at $30 \mathrm{hPa}$ around $65^{\circ} \mathrm{N}$, i.e. at 5 degrees lower latitudes than in SVR episodes, and west wind is reduced north of $75^{\circ} \mathrm{N}$. Changes in the strength of the subtropical jet are mainly due to transient planetary waves (not shown here) and therefore we do not see any significant anomalies of EP flux divergence in the subtropical upper troposphere for stationary waves. 

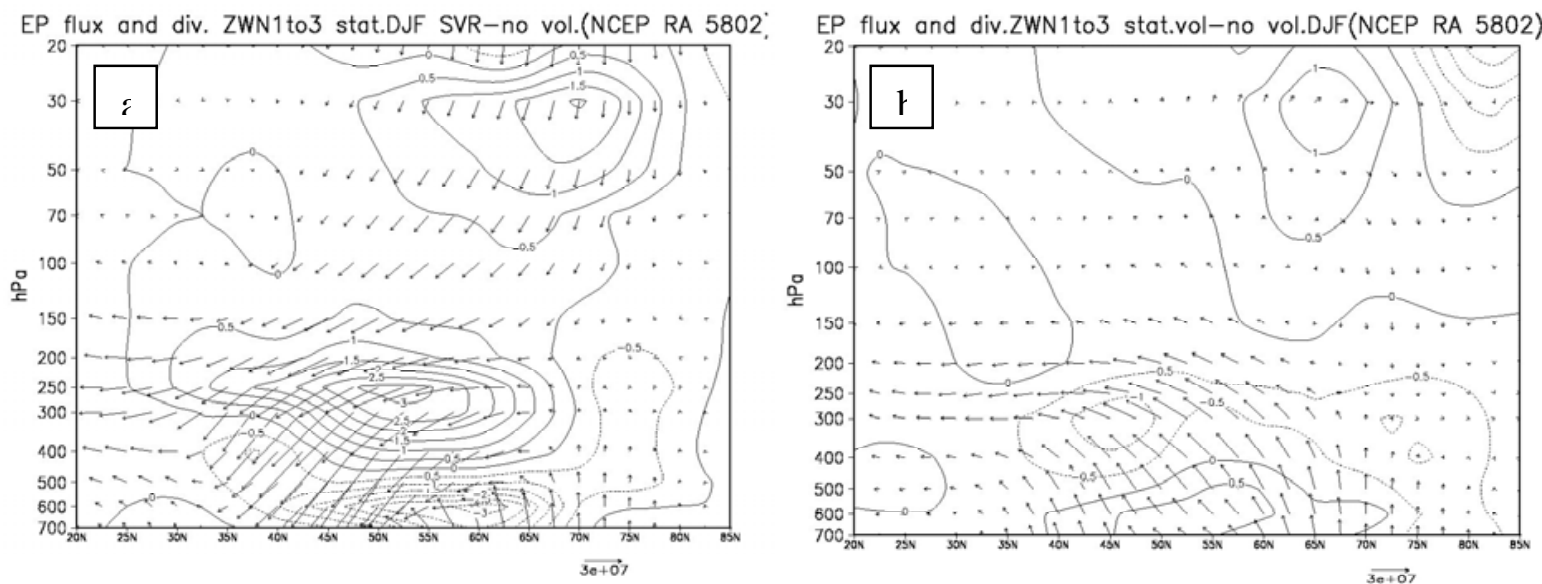

Fig. 5. EP flux and its divergence (ZWN1+2+3): (a) difference between non-volcanic SVR episodes and non-volcanic winters; (b) difference between volcanic winters and non-volcanic winters. Divergence contour interval is $0.5 \mathrm{~ms}-1$ day- 1 , the unit of vector is kg s- 2 .

\section{Discussion and conclusions}

Our analysis of the planetary wave propagation conditions under volcanic impact showed that, while in winters after volcanic eruptions the polar vortex often is strengthened, a sustained excitation of the strong polar vortex regime could not be observed and the anomalies are weaker than during SVR episodes. Instead of effective blocking of upward travelling planetary waves in the lower stratosphere, in volcanically influenced winters planetary wave propagation into the upper stratosphere is facilitated according to our study of reanalysis data. Furthermore, the observed generation of planetary waves is enhanced in volcanic winters in the troposphere, mainly of ZWN1. This is different from the model simulations reported by Stenchikov et al. (2002). The question remains if the enhanced EP flux is due to the effects of concurrent El Nino events, which were excluded in the model simulations. Model results of Manzini et al. (2006), Sassi et al. (2004) and Garcia-Herrera et al. (2005) show increased planetary wave amplitudes after El Nino and a weaker polar vortex at some stage through the following winter. These studies, however, do not account for simultaneous volcanic forcing.

Enhanced vertical EP flux in our volcanic winters is due to ZWN1 waves. ZWN 2 activity is reduced in the troposphere and, therefore, also in the stratosphere. About 33\% of the EP flux from stationary planetary waves that are observed near the tropopause reaches the upper stratosphere in volcanic winters. This is more than during all other winter times. The planetary wave energy reaching the upper stratosphere is maximal also in absolute terms in winters after strong volcanic eruptions. When these waves brake, they can even lead to strong stratospheric warmings. This was observed e.g. in mid January 1992 after the eruption of Mt. Pinatubo, when the polar vortex nearly broke down.
The frequency distribution of negative squared refractive indices on the meridional plane would allow a higher ratio of planetary wave energy to reach the upper stratosphere also in SVR episodes. However, in these cases a second branch of propagation is preferred by the planetary waves and they transport momentum near the tropopause towards the subtropics. In SVR the upper tropospheric westerly winds are strongly enhanced between $40^{\circ} \mathrm{N}$ and $60^{\circ} \mathrm{N}$ compared with all non-volcanic winters, but in volcanic winters they are much less so. Hence, while after volcanic eruptions and during SVR regimes similar climate anomalies are being diagnosed in mid and high latitudes of the Northern Hemisphere in the lower troposphere, their causes are dissimilar. Obviously a subtle balance of all the parameters determining planetary wave propagation is finally decisive of the pathway of planetary wave energy.

As was shown in several previous studies, the effects of volcanic eruptions regarding temperature or precipitation anomalies at the surface are very similar to those observed during SVR episodes: continental winter warming and northward shift of storm tracks. An explanation for this may be found in the studies of Perlwitz and Harnik (2003 and 2004), where they showed that a zonal wave number one anomaly can propagate up to the stratopause and be reflected there at a layer of strong negative vertical wind shear. Actually, the winters (JFM) of 1992 and 1993 were defined as "reflective" by Perlwitz and Harnik (2004) based on their index measuring the shear of zonal mean wind averaged from $58^{\circ} \mathrm{N}$ to $74^{\circ} \mathrm{N}$ between $2 \mathrm{hPa}$ and $10 \mathrm{hPa}$, while the winters after El Chichon (JFM 1983 and 1984) were not, although the index was slightly smaller than -0.25 standard deviations, i.e. on the refractive side (Perlwitz and Harnik, 2003). The time after the Gunung Agung eruption was not included in their study. If the waves are not reflected they may eventually 
break and change the mean circulation. This signal can then slowly propagate down into the troposphere as is observed during major stratospheric warmings. This would lead to climate anomalies of the opposite sign than observed after volcanic eruptions, i.e. continental cooling in winter. Wave breaking and stratospheric warming after volcanic eruptions obviously does not occur frequently, though it is possible. Otherwise we would not find such robust anomaly patterns after a large number of significant eruptions (Robock, 2000).

Climate model studies of the volcanic effects often produce a less robust winter warming and less enhanced polar stratospheric vortex and this may be due to more frequent wave breaking in the models or, alternatively, to a bias in the planetary wave energy that is being carried by ZWN 1 and 2 . Since most of the EP flux reaching the upper stratosphere is from ZWN 1 and the flux of ZWN 2 is reduced in volcanic winters, a redistribution of energy from ZNW 1 to ZWN 2 would reduce the energy that can be reflected downwards from the upper stratosphere. We would like to stress that during the winters after all three volcanic eruptions we investigated here El Ninos took place, an even very strong one in 1982/83 after the El Chichon eruption. To what degree they influenced the atmospheric response to volcanic forcing will have to be investigated with climate models that can resolve the dynamical processes mentioned above. According to our results the dominating dynamical process of volcanic aerosol disturbing winter circulation and climate is suggested to be wave reflection at the stratopause region. Any climate models that do not dynamically resolve the stratopause region will have problems representing these processes described above. We suggest that this may have contributed to their failure of simulating the correct amplitude of tropospheric climate anomalies after big tropical volcanic eruptions.

If our interpretation (reflection of waves back to the troposphere from the upper stratosphere) of the analysis of planetary wave propagation after significant volcanic eruptions is accurate, this implies that we have to expect a main impact of volcanic eruptions with a ZWN1 pattern, i.e. the North Atlantic Oscillation would be most affected. Northern Annular Mode or any other zonal mean based variability measure could be excluded from being involved since these modes would require planetary wave breaking. Unfortunately the data we used do not allow investigating these mechanisms in more detail. This will be done in the near future using ERA40 reanalyses.

Acknowledgements. Q. Li's work was funded by the German Federal Government within the AFO2000 KODYACS project and by the International Max-Planck Research School in Hamburg. We thank P. Braesicke for comments on an earlier version of the manuscript.

Edited by: W. E. Asher

\section{References}

Andrews, D. G., Holton, J. R., and Leovy, C. B.: Middle Atmosphere Dynamics. Academic Press Inc., 489 pp, 1987.

Angell, J. K. and Korshover, J.: Comparison of stratospheric warming following Agung and Chichon, Mon. Weather Rev., 111, 2129-2135, 1983.

Bradley, R. S.: The Explosive Volcanic-Eruption Signal in Northern Hemisphere Continental Temperature Records, Climatic Change, 12(3), 221-243, 1988.

Castanheira, J. M., and Graf, H.-F.: North Pacific-North Atlantic relationships under stratospheric control?, J. Geophys. Res., 108, 4036, doi:10.1029/2002JD002754, 2003.

Charney, J. G. and Drazin, P. G.: Propagation of planetary-scale disturbances from the lower into the upper atmosphere. J. Geophys. Res., 66, 83-109, 1961.

Feser, F., Graf, H.-F., and Perlwitz, J.: Secular variability of the coupled tropospheric and stratospheric circulation in the GCM ECHAM3/LSG, Theor. Appl. Clim., 65 1/2, 1-15, 2000.

Garcia-Herrera, R., Calvo, N., Garcia, R. R., and Giorgetta, M. A.: Propagation of ENSO temperature signals into the middle atmosphere: A comparison of two general circulation models and ERA-40 reanalysis data. J. Geophys. Res., 111, D06101, doi:10.1029/2005JD006061, 2006.

Graf, H.-F.: Arctic radiation deficit and climate variability, Climate Dyn., 7, 19-28, 1992.

Graf, H.-F., Kirchner, I., Robock, Q., and Schult, I.: Pinatubo eruption winter climate effects: model versus observations, Clim. Dyn., 9, 81-93, 1993.

Groisman, P. Y.: Possible Regional Climate Consequences of the Pinatubo Eruption - an Empirical-Approach, Geophys. Res. Lett., 19 (15), 1603-1606, 1992.

Kalnay, E., Kanamitsu, M., Kistler, R., Collins, W., Deaven, D., Gandin, L., Iredell, M., Saha, S., White, G., Woollen, J., Zhu, Y., Chelliah, M., Ebisuzaki, W., Higgins, W., Janowiak, J., Mo, K. C., Ropelewski, C., Wang, J., Leetmaa, A., Reynolds, R., Jenne, R., and Joseph, D.: The NCEP/NCAR 40-year reanalysis project, Bull. Amer. Meteor. Soc., 77, 437-472, 1996.

Kelly, P. M., Jones, P. D., and Jia, P. Q.: The spatial response of the climate system to explosive volcanic eruptions, Int. J. Climatol., 16 (5), 537-550, 1996.

Kirchner, I., Stenchikov, G. L., Graf, H. F., Robock, A., and Antuna, J. C.: Climate model simulation of winter warming and summer cooling following the 1991 Mount Pinatubo volcanic eruption, J. Geophys. Res.-Atmos., 104 (D16), 19 039-19 055, 1999.

Kodera K., Chiba, M., Yamazaki K., et al.: A possible influence of the polar night stratospheric jet on the subtropical tropospheric jet, J. Meteorol. Soc. Japan, 69(6), 715-721, 1991.

Kodera, K.: Influence of volcanic eruptions on the troposphere through stratospheric dynamical processes in the northern hemisphere winter, J. Geophys. Res., 99, 1273-1282, 1994.

Kistler, R., Kalnay, E., Collins, W. S. Saha,White, G., Woollen, J., Chelliah, M., Ebisuzaki, W., Kanamitsu, M., Kousky, V., van den Dool, H., Jenne, R., and Fiorino, M.: The NCEP-NCAR 50-year reanalysis: Monthly means CD-ROM and documentation, Bull. Amer. Meteor. Soc., 82, 247-268, 2001.

Li, Q., Graf, H.-F. and Giorgetta, M.: Stationary planetary wave propagation in Northern Hemisphere winter - climatological analysis of the refractive index, Atmos. Chem. Phys., 7, 183200, 2006, 
http://www.atmos-chem-phys.net/7/183/2006/.

Manzini, E., Giorgetta, M. A., Esch, M., Kornblueh, L., Roeckner, E.: The influence of sea surface temperatures on the northern winter stratosphere: Ensemble simulations with the MAECHAM5 model, J. Climate, 19 (16), 3863-3881, 2006.

Mao, J., and Robock, A.: Surface air temperature simulations y AMIP general circulation models: Volcanic and ENSO signals and systematic errors, J. Clim., 11, 1538-1552, 1998.

Mass, C. F. and Portman, D. A.: Major volcanic eruptions and climate: A critical evaluation, J. Clim., 2, 566-593, 1989.

Matsuno, T.: Vertical propagation of stationary planetary waves in the winter Northern Hemisphere, J. Atmos. Sci., 27, 871-883, 1970.

Miller, R. L., Schmidt, G. A., and Shindell, D. T.: Forced annular variations in the 20th century Intergovernmental Panel of Climate Change Fourth Assessment Report models, J.Geophys. Res., Vol.111, D18101, doi:10.1029/2005JD006323, 2006

Perlwitz, J. and Harnik, N. : Observational evidence of a stratospheric influence on the troposphere by planetary wave reflection, J. Climate, 16, 3011-3026, 2003.

Perlwitz, J. and Harnik, N.: Downward coupling between the Stratosphere and Troposphere: The relative roles of wave and zonal mean process, J. Climate, 17, 4902-4909, 2004.
Robock, A. and Mao, J.: Winter warming from large volcanic eruption, Geophys. Res. Lett., 19, 2405-2408, 1992.

Robock, A.: Volcanic eruptions and climate, Rev. Geophys., 38, 191-219, 2000.

Sassi F., Kinnison D., Boville, B. A., Garcia, R. R., and Roble, R.: Effect of El Nino-Southern Oscillation on the dynamical, thermal, and chemical structure of the middle atmosphere, J. Geophys. Res., 109, (D17), D17108, Sep. 14, 2004.

Shindell, D. T., Schmidt, G. A., Miller, R. L., and Rind, D.: Northern Hemisphere winter climate response to greenhouse gas, ozone, solar, and volcanic forcing, J. Geophys. Res., 106, 7193 7210, 2001.

Stenchikov, G., Robock, A., Ramaswamy, V., Schwarzkopf, M., Hamilton, K., and Ramachamdran, S.: Arctic Oscillation response to the 1991 Mount Pinatubo eruption: Effectis of volcanic aerosols and ozone depletion, J. Geophy. Res., 107, (D24), 4803, doi:10.1029/2002JD002090, 2002.

Stenchikov, G., Hamilton, K., Stouffer, R. J., Robock, A., Ramaswamy, V., Santer, B., and Graf, H.-F.: Climate impacts of volcanic eruptions in the IPCC AR4 climate models, J. Geophys. Res., 111, D07107, doi:10.1029/2005JD006286, 2006. 